\title{
Enthalpy-entropy compensation for isosteric state adsorption at near ambient temperatures
}

\author{
Andrzej Mianowski ${ }^{1}$ Wojciech Urbańczyk ${ }^{1}$
}

Received: 23 January 2017 / Revised: 21 June 2017 / Accepted: 21 July 2017 / Published online: 9 August 2017

(C) The Author(s) 2017. This article is an open access publication

\begin{abstract}
The adsorption process at near ambient temperatures indicated that the EEC (enthalpy-entropy compensation) is affected by three basic thermodynamic values: $\Delta H$, $\Delta S$ and $T$. The consequence is that it is possible to determine an isosteric straight (symbol $H-S$ ) without experimental studies based on the slope coefficient $T_{i s o}$, which is the constant arising from the expected temperature range (about 0-60 ${ }^{\circ} \mathrm{C}$ ). Therefore, EEC curves can be obtained by appropriate modification of the temperature range. In the case of entropy of adsorption, the decisive influence is the entropy of gas. For visualization and characterization of this impact, we proposed resolute pointer $\mu$ (Eq. 25), through which it is observed that for small values of the equilibrium vapor pressure, as $\mathrm{P} \rightarrow 0$, there are significant deviations from the isosteric straight $H-S$. The case where $P \rightarrow P_{0}$ followed a gradual grouping of experimental data in accordance with the relationship with $H-S$. We used the three-parameter equation for exothermic processes. For the extrapolated conditions, the so-called point of zero adsorption represented the enthalpy and entropy of adsorption, whose values are analogous to previous results in the literature, which can be considered an appropriate analytical method to determine these two thermodynamic values.
\end{abstract}

Keywords Gas adsorption · Enthalpy vs. entropy · Threeparametric equation

Wojciech Urbańczyk

Wojciech.Urbanczyk@polsl.pl

1 Department of Inorganic Chemistry, Analytical Chemistry and Electrochemistry, Faculty of Chemistry, Silesian University of Technology, Bolesława Krzywoustnego 6 Street, 44-100 Gliwice, Poland

\section{List of symbols}

AA, LA

$a$

$a_{0}, a_{1}, \mathrm{a}_{2}, a_{3}, a_{4}, a_{5}$

C

$c_{p}$ or $\Delta c_{p}$

EEC or KCE

$h$

$H-S$

$P$

$q$

$R$

$r^{2}$

$s$

s.l.

$T$

V

$\delta S$

$\Delta G, \Delta H, \Delta S$

$\mu$
Arithmetic and logarithmic average, respectively

Amount adsorbed at equilibrium, mmol g ${ }^{-1}$ or $\mathrm{cm}^{3} \mathrm{~g}^{-1}$

Coefficients of the three-parametric equation, Eq. (27) and remarks

Constant in Eq. (26)

Heat capacity or heat capacity of the process, $\mathrm{J} \mathrm{mol}^{-1} \mathrm{~K}^{-1}$

Enthalpy-entropy compensation or kinetics compensation effect

Enthalpy, $\mathrm{J} \mathrm{mol}^{-1}$

Isosteric function

Pressure, $\mathrm{Pa}$

Heat of adsorption, $\mathrm{J} \mathrm{mol}^{-1}$

Universal gas constant,

$\mathrm{R}=8.314 \mathrm{~J} \mathrm{~mol}^{-1} \mathrm{~K}^{-1}$

Coefficient of linear determination,

$0 \leq \mathrm{r}^{2} \leq 1$

Entropy, $\mathrm{J} \mathrm{mol}^{-1} \mathrm{~K}^{-1}$

Significance level

Temperature, $\mathrm{K}$

Adsorbed phase volume, $\mathrm{m}^{3} \mathrm{~mol}^{-1}$

Inexact differential entropy,

$\mathrm{J} \mathrm{mol}^{-1} \mathrm{~K}^{-1}$

Thermodynamic functions, $\mathrm{J} \mathrm{mol}^{-1}$ or $\mathrm{J} \mathrm{mol}^{-1} \mathrm{~K}^{-1}$

Indicator which assumes isoentropic condition 


\section{Subscripts and superscripts}

a

$\bar{a}$

diff

$e q$

G

$i$

iso

$S$

st

$o$

$\varnothing$
Amount adsorbed at equilibrium, mmol g ${ }^{-1}$ or $\mathrm{cm}^{3} \mathrm{~g}^{-1}$, respectively Dimensionless of relative amount adsorbed at equilibrium, $\mathrm{mol} \mathrm{mol}^{-1}$ Differential

Equilibrium state

Gas state

Initial stage

Refers to isokinetic point

Solid state

Isosteric state

Refers to saturated vapor pressure

Standard condition for ideal gas

\section{Introduction}

In many thermodynamic analyses of chemical reactions/ processes, it has been experimentally demonstrated that there are linear dependencies for the standard thermodynamic function, named the EEC compensation effect (enthalpy-entropy compensation) [(Sharp 2001; Marco and Linert 2002; Ryde 2014; Olsson et al. 2008; Dutronc et al. 2014; Klebe 2015) KCE (Norwisz and Musielak 2007; Lvov 2007)]. According to Starikov, the relevant entry is expressed as follows (Starikov 2014):

$\Delta H=T_{i s o} \Delta S+\Delta H_{i s o}$

where the slope coefficient is constant and is named the isokinetic temperature, and the intercept $\Delta H_{i s o}$ which is part of enthalpy, is replaceable in isoentropic conditions $(\Delta S=0)$.

Studies have shown that EEC also occurs during the adsorption of low molecular weight gases on active surfaces (Burevski et al. 1991; Fletcher and Thomas 2000; Garrone et al. 2008; Korolev et al. 2011; Hercigonja and Rakić 2013; Pera-Titus 2016; Zukal et al. 2009; Kelut et al. 2014), wherein the dependence isn't necessarily linear, as Eq. (1) in unequivocal manner (Fletcher and Thomas 2000; Garrone et al. 2008). The analysis in Eq. (1) requires the selection of the sorbent, adsorbate and experimental conditions, which allows the interpretation of observations of one of two possibilities:

a. one system for several temperatures,

b. several systems with varying selected factors side of the sorbent or adsorbate.

In addition, the instrumental technique also has a huge impact; in general, most research uses adsorption/desorption isotherms and converts them into isolines at constant amounts of adsorbed substances at varying temperatures.

Tested systems with repetitive features are well described, such as zeolite-CO $\mathrm{CO}_{2}$ (Burevski et al. 1991; Pera-Titus 2016; Zukal et al. 2009; Kelut et al. 2014). In (Pera-Titus 2016), the literature data show another form of EEC resulting from (1), namely:

$\Delta H=n(T \Delta S)+m, \quad n, m=$ const

where it is postulated according to (Starikov 2014) that the isokinetic enthalpy (the absolute) is $15 \mathrm{~kJ} \mathrm{~mol}^{-1}$ (Pera-Titus 2016).

Comparison of Eqs. (1) and (2) indicates that a primary issue in the analysis of the EEC is how to determine the entropy because of its definition in the adsorption process. The exothermic adsorption process is characterized in terms of thermodynamic categories as the difference in the function $H-S$ with respect to the adsorbate in two phases: solid minus gas. Moreover, these issues are of great importance in practice in multifunctional systems [cooling, heating (Borsukiewicz-Gozdur and Nowak 2007; Aphornratana and Eames 1995; Sumathy et al. 2003; Hassan et al. 2011; Gwadera and Kupie 2011)] implemented by adsorption/desorption using effectively low-energy gases (Borsukiewicz-Gozdur and Nowak 2007; Gwadera and Kupie 2011).

\section{Purpose and scope of studies}

The work aims to analyze Eq. (1) for this type of research. The basic problem is the designation of the entropy of adsorption, which is usually overlooked in this type of work. These capabilities only exist when the use of the thermodynamic equilibrium constant is skipped, e.g., (Madamba et al. 1996; Beristain et al. 1996; Al-Muhtaseb et al. 2004, 2007; Pedro and Babas 2005; Ramesh et al. 2005; Tang et al. 2006; Palomino et al. 2008; Musa et al. 2010; Loto et al. 2012) as these cases do not require comments, and for non-pressure processes, when $P / P_{o}<1$.

The scope of this work includes:

1. analysis of the EEC using classic research methods in isosteric conditions,

2. use of a three-parameter equation for the discussed issue,

3. comparison of these issues.

The factors outlined above were analyzed using literature data (Zukal et al. 2009) and alternatively (Burevski et al. 1991).

\subsection{The accepted theoretical dependencies}

To analyze the EEC problem in the case of gas adsorption on an active surfaces, the huge role of the $H-S$ relationship 
satisfies the priority assumption of the initial state. Specifically, it should be established which of the two values, higher enthalpy $\left(\Delta H, J \mathrm{~mol}^{-1}\right)$ or approximately $10^{3}$ times lower entropy $\left(\Delta S, \mathrm{~J} \mathrm{~mol}^{-1} \mathrm{~K}^{-1}\right)$, is advantageous as a starting point.

In the literature, there is consensus that the isosteric enthalpy of adsorption designates the slope coefficient in a system: $\ln P$ versus $1 / T$, which is represented for an ideal gas and next as $R T / P=V_{G}>>>V_{S}$ :

$\left(\frac{\partial \ln P}{\partial\left(\frac{1}{T}\right)}\right)_{a}=\Delta H / R$

$\Delta H=h_{S}-h_{G}$

where the index $\mathrm{S}$ refers to gas adsorbed in the solid phase (the surface) and $\mathrm{G}$ represents gas.

In Eqs. (3) and (4), $\Delta H$ is the isosteric enthalpy of adsorption $\left(\Delta H<0\right.$ and $\left.q^{s t}=-\Delta H\right)$, which is practically the same as the differential molar enthalpy $\left[q^{\text {diff }}=q^{\text {st }}-R T\right.$ (Terzyk et al. 2016; Gauden et al. 2016; Kowalczyk et al. 2017), and this is $\Delta H^{\text {diff }}=\Delta H+R T$ what logical consequence is $\Delta H \equiv \Delta H^{s t}$.

In the case of the tested system of solid phase and gas, the isosteric heat of adsorption in view of $a$ is either:

a. constant (Czepirski and Jagiełło 1989; Sircar et al. 1999; Stadie et al. 2012),

b. monotonically decreasing (Burevski et al. 1991; PeraTitus 2016; Zukal et al. 2009; Terzyk et al. 2016; Gauden et al. 2016; Kowalczyk et al. 2017; Czepirski and Jagiełło 1989; Sircar et al. 1999; Stadie et al. 2012; Barrer and Gibbons 1963a; Guo et al. 2006),

c. anomalous (increase and decrease) (Terzyk et al. 2016; Gauden et al. 2016; Kowalczyk et al. 2017; Stadie et al. 2012),

where $a$ is understood as the number of moles or volume of substance adsorbed by a unit mass of adsorbate.

The considerations for the designation of the entropy of adsorption (also $\Delta S<0$ ) are more complicated.

Based on the Gibbs free energy equation, taking into account the second law of thermodynamics:

$\Delta G=\Delta H-T \Delta S$

We assume that the isosteric adsorption process occurs under equilibrium:

$\Delta G \equiv 0$

that is:

$\Delta H=T \Delta S$ where consistently:

$\Delta S=s_{S}-s_{G}$

By inserting Eq. (7) into (3), we obtain:

$\left(\frac{\partial \ln P}{\partial \ln T}\right)_{a}=-\Delta S / R$

The left sides of Eqs. (3) and (9) and Eq. (5) confirm the validity of (6).

The isosteric heat of adsorption implies isosteric entropy in terms of determination. Equation (9) can be obtained in another way, namely, for a perfect gas and following the assumptions for Eq. (3) for a constant amount of adsorbed adsorbate and adsorbent surface [Eq. (3.114) in (Ościk 1983)].

$\Delta S=-R T\left(\frac{\partial \ln P}{\partial T}\right)_{\bar{a}}$

A purely mathematical transformation $\left(T^{-1} \partial T=\partial \ln T\right)$ of Eq. (10) produces Eq. (9). However, insertion of the transformed Eq. (3) into Eq. (10) produces Eq. (7):

$\Delta S(P)=\frac{\Delta H}{T}$

According to (10), entropy is the differential molar entropy of adsorption, and $\Delta S(P)$ is also in equilibrium [Eqs. (3.124) and (3.128) in (Ościk 1983)].

Entropy expressed as Eq. (9) is the average value within the range of tested temperatures, similar to the case of enthalpy in (3). The main difference is that the entropy presented in Eq. (11) is temperature-dependent, but the average value is compatible with Eq. (7).

For the entropy of the gas phase, $s_{G}$, the relationship with temperature and pressure should be considered.

The change in entropy of a gas follows from:

$d s_{G}=c_{p} \frac{d T}{T}-\left(\frac{\partial V}{\partial T}\right)_{p} d P$

which for an ideal gas can be written as:

$d s_{G}=c_{p} \frac{d T}{T}-R \frac{d P}{P}$

Because $d s_{G}$ is an exact differential, for the two thermodynamic states marked as 1 and $\underline{2}$, we get:

$s_{G, 2}-s_{G, 1}=c_{p} \ln \left(\frac{T_{2}}{T_{1}}\right)-R \ln \left(\frac{P_{2}}{P_{1}}\right)$

In isothermal conditions, in cases (13) and (14), based on the first expression of the right sides of these equations, we get:

$s_{G, 2}-s_{G, 1}=-R \ln \left(\frac{P_{2}}{P_{1}}\right)$ 
which for further considerations is preferably written as:

$s_{G, 1}=s_{G, 2}+R \ln \left(\frac{P_{2}}{P_{1}}\right)$ for $T=$ const and $\ln \left(\frac{T_{2}}{T_{1}}\right) \approx 0$

Indeed, in the field of isosteric research, for the most common temperature interval $\left(t=20-40{ }^{\circ} \mathrm{C}\right)$ and the most commonly used gases, the effect of temperature on the entropy is on the order of: $\delta s=0.066 c_{p}=2-3 \mathrm{~J} \mathrm{~mol}^{-1} \mathrm{~K}^{-1}$ [e.g., $\mathrm{CO}_{2} c_{p}=37.132 \mathrm{~J} \mathrm{~mol}^{-1} \mathrm{~K}^{-1}$ (Barin 1997)], which corresponds to the difference between the average entropy expressed as Eq. (9) and according to (11).

Enter to the Eq. (11) the symbol $\Delta S(P)$ relative to $\Delta S$ is expedient, as it is necessary to emphasize the point of reference of the entropy of a gas depending on the equilibrium pressure.

In the case of Eq. (11), the point of reference relates the equilibrium pressure to a vacuum, and there are two further possibilities to determine Eqs. (17) and (18) for:

- standard pressure $\mathrm{P}^{\varnothing}=101.325 \mathrm{kPa}$ (1 bar) (Burevski et al. 1991; Guo et al. 2006; Eq. (12) in Barrer and Gibbons 1963b; Clark 1970, p. 39; Eq. (2.70) in Rouquerol et al. 1999)

$$
\Delta S\left(P^{\emptyset}\right)=s_{S}-s_{G}\left(P^{\emptyset}\right)=\frac{\Delta H}{T}+R \ln \left(\frac{P^{\emptyset}}{P}\right)
$$

where $s_{G}\left(P^{\emptyset}\right)=s_{G}{ }^{\emptyset}$ is for the standard state at temperature $T$; consequently, according to (Terzyk et al. 2016; Gauden et al. 2016; Kowalczyk et al. 2017), we get: $\Delta S\left(P^{\emptyset}\right)^{\text {diff }}=\Delta S\left(P^{\emptyset}\right)+2 R$.

- the saturated vapor pressure, $P_{0}$, in commonly used terms, arises from the Gibbs free energy (5) and at the same time is equal to $\Delta G=R T \ln \left(\frac{P}{P_{0}}\right)$

$\Delta S\left(P_{0}\right)=s_{S}-s_{G}\left(P_{0}\right)=\frac{\Delta H}{T}+R \ln \left(\frac{P_{0}}{P}\right)$

Eqs. (11), (17) and (18) can be subjected to linear combinations, in accordance with Eq. (16). For example, presenting Eq. (8) as:

$\Delta S(P)=s_{s}-s_{G}(P)$

and substituting Eq. (16) in place of $s_{G}(P)$, wherein substituting $P$ for state 1 , and $P_{o}$ for state $\underline{2}$, we get:

$\Delta S(P)=s_{s}-\left[s_{G}\left(P_{\mathrm{o}}\right)+R \ln \left(\frac{P_{0}}{P}\right)\right]$

which is equivalent to:
$\Delta S(P)=\Delta S\left(P_{o}\right)-R \ln \left(\frac{P_{0}}{P}\right)$

After using Eq. (11), we again obtain Eq. (18).

Additionally, the ability to convert from a vacuum state to standard pressure can be obtained by adding the respective fixed $\operatorname{sign}\left|R \ln \frac{1 \mathrm{bar}}{1 \text { torr }}\right|=55.04 \mathrm{~J} \mathrm{~mol}^{-1} \mathrm{~K}^{-1}$ (Garrone et al. 2008).

These considerations indicate the interpretation of the entropy of adsorption as a multi-variant measure to assess the equilibrium state in the sense of Eqs. (5) and (11), which can be related to other observation states, even by addition, with the correct sign, by the factor $R \ln \left(\frac{P_{2}}{P_{1}}\right)$ in Eqs. (17) and (18).

In isosteric research, entropy can be represented by four relations: (10) the average value invariant of temperature over a range and three, according to Eqs. (11), (17) and (18), which is temperature-dependent. Equations (17) and (18), relative to Eq. (11), differ by the addition of $R \ln \left(\frac{P_{2}}{P_{1}}\right)$, where $P_{2}>P_{1}$, which is an important factor because of the introduced adsorbate.

Finally, we have a case of one invariant size of isosteric heat of adsorption according to (3), which is correlated with the invariant entropy in Eqs. (9), (17) and (18).

Ultimately, only Eqs. (9) and (18) remain because the trends of Eq. (17) can be considered as an intermediate state.

\subsection{Analysis of EEC in relation to Eqs. (3) and (9)}

For EEC purposes, sizes should be used the values corresponding to the same categories of their determination in this case, the average values, independent of temperature in the range, i.e., (3) and (9).

Each of the analyzed cases produces are linear relationship depending on Eq. (1). In all cases, the intercept is less than $1 \mathrm{~kJ} \mathrm{~mol}^{-1}$, so it can be omitted, and the passes through the origin of the Cartesian system. Figure 1 shows an example.

Both thermodynamic functions are invariant with respect to temperature, but it is worth analyzing their behavior in this temperature range. This relationship can be derived from Kirchhoff's equations by comparing the hypothetical heat capacity of the adsorption process $\Delta c_{p}=$ const:

$\frac{\Delta H-\Delta H_{i}}{\Delta S-\Delta S_{i}}=\frac{T-T_{i}}{\ln \left(\frac{T}{T_{i}}\right)}, \quad \frac{d \Delta c_{p}}{d T}=0$

where index $i$ represents a measurement at temperature $T_{i}$, and $\Delta H$ and $\Delta S$ are the average values, respectively, from Eqs. (3) and (9). 
Fig. 1 Version of EEC using Eqs. (3) and (9) [data from (Zukal et al. 2009)]

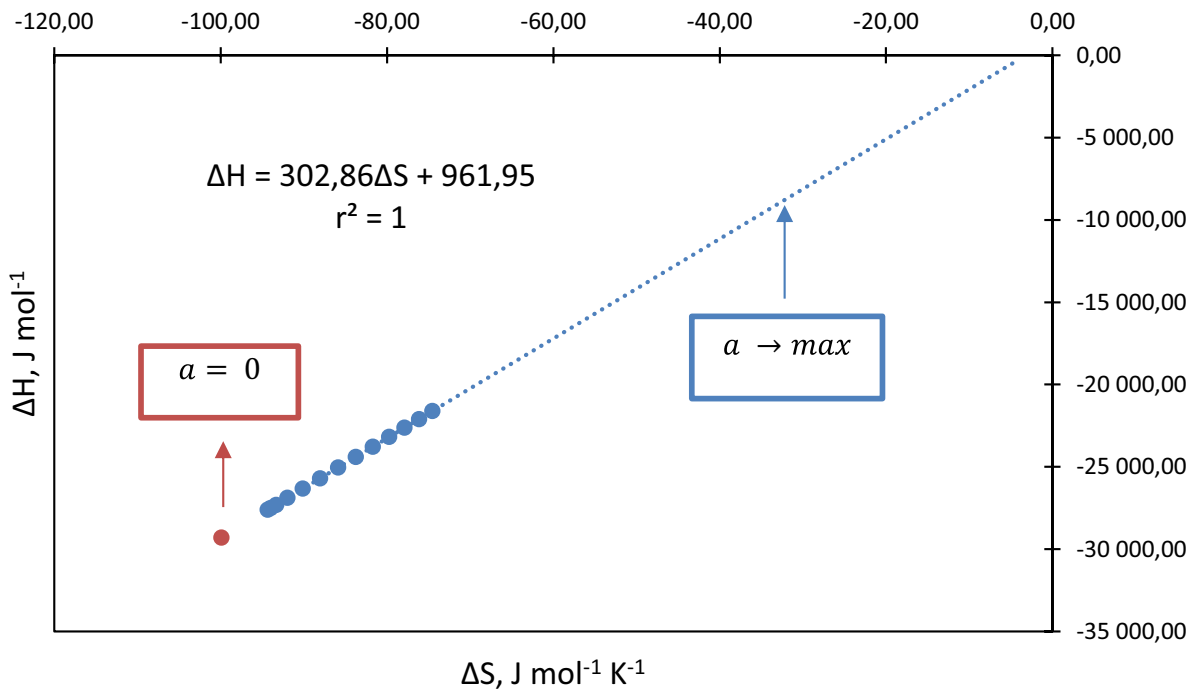

For small ranges of variation $\left(T-T_{i}\right)$ and for $0<T / T_{i} \leq 2$, the expression under the logarithm can be replaced by the first member from the series:

$\ln \left(\frac{T}{T_{i}}\right)=\ln y=(y-1)-\frac{1}{2}(y-1)^{2}+\frac{1}{3}(y-1)^{3} \ldots$

Thus, the logarithmic average can be replaced by one temperature, $T_{i}=T_{i s o}$, and Eq. (22) because Eq. (23) can be represented as a specified form of Eq. (1):

$\Delta H=T_{i s o} \Delta S+\left(\Delta H_{i}-T_{i s o} \Delta S_{i}\right)$

The expression in brackets has an intercept that may be close to 0 .

For the forms designated experimentally in the Eq. (24), if the intercept is omitted, then Eq. (11) can be interpreted differently, namely, if both thermodynamic functions are temperature-invariant, their volatility is directly proportional to a proportionality factor corresponding to a constant isokinetic temperature. Equation (24) can be called isosteric straight, $H-S$.

In Eq. (24), the version without the intercept $\left(\Delta H=T_{i s o} \Delta S\right)$ presents interesting information. In the specified temperature range, the trend lines of EEC can be sketched a priori. $T_{\text {iso }}$ is the logarithmic average, and in a narrow temperature range, it is the arithmetic average of the upper and lower temperature. Therefore, for the same data, in a narrow range of temperature, the slope coefficient is decreased by reducing $T_{i s o}$. This means that there are additional grouping results. In the ideal case, the interpretation of the same experimental data in the EEC system is presented in Fig. 2.
Fig. 2 The dependence of $\Delta H$ versus $\Delta S$ depends on the accepted temperature interval based on Eqs. (3) and (9). $T_{\text {iso }}$ is decreased by narrowing the temperature range [data from (Zukal et al. 2009)]. $A A$ arithmetic average, $L A$ logarithmic average

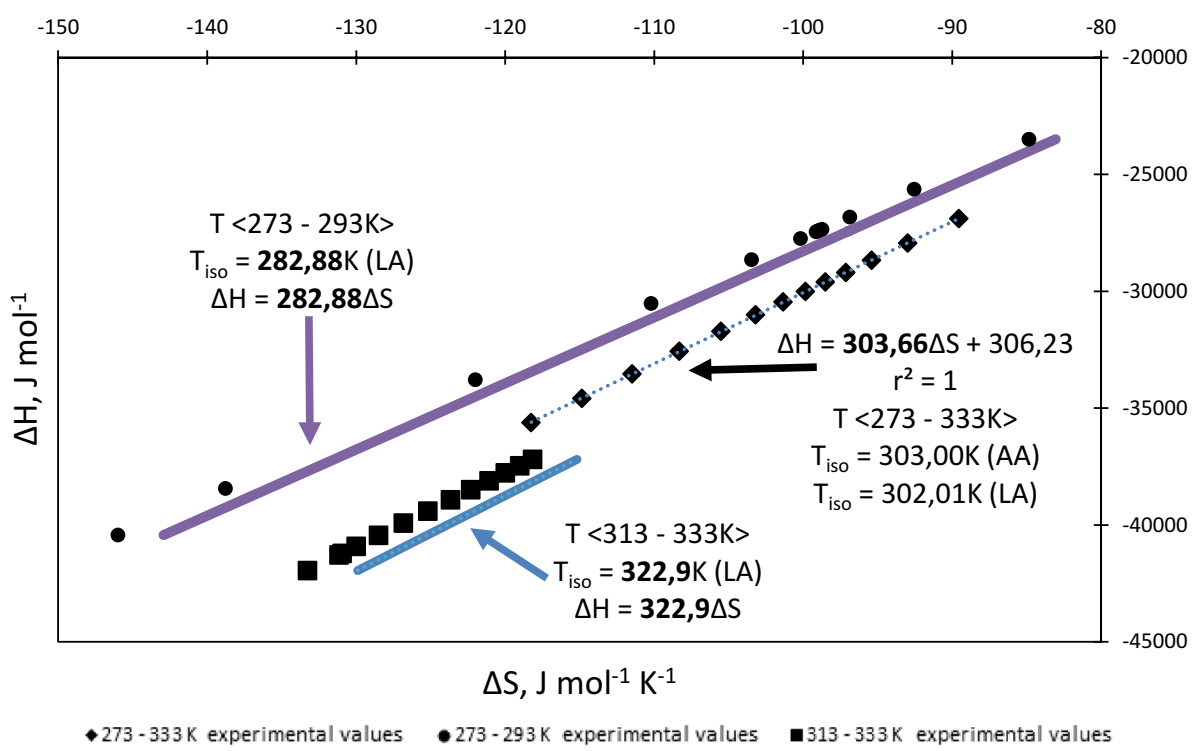


Fig. 3 EEC system for various of literature data Eqs. (3) and (18) and isosteric straight (light blue) based on Eqs. (3) and (9) (temperature range 273-333 K) [data $a, b, c, d$ from Fig. 2 a, $\mathrm{b}, \mathrm{c}, \mathrm{d}$ and $e, f$ from Fig. $3 \mathrm{a}, \mathrm{b}$ in (Zukal et al. 2009)] ( $x$ - see Fig. 4a). (Color figure online)
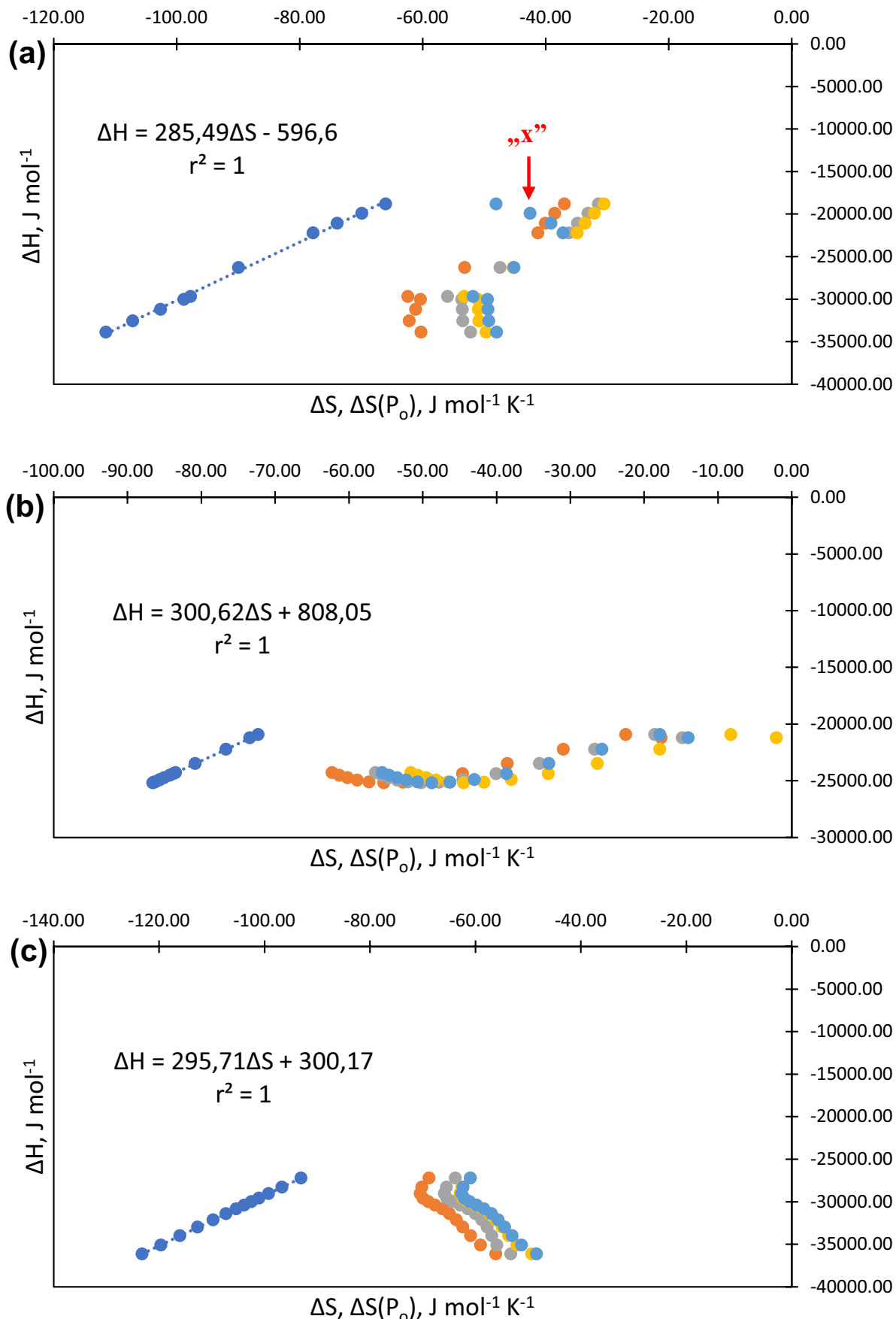

\subsection{Analysis of the EEC for other forms of entropy}

In view of the considerations above, the EEC forms in the combined versions of Eqs. (3) and (9) and Eqs. (11) and (24), it remains to examine the EEC relationship in version Eq. (3), in association with Eq. (17) and Eq. (18). For clarity, Fig. 3 shows the results of analysis in an EEC system omitting Eq. (17).

For small values of $P \rightarrow 0$ in Eq. (18), the expression $R \ln \left(\frac{P_{0}}{P}\right)$ is large; therefore, we observe significant deviation from the isosteric straight $H-S$ (24). As $P \rightarrow 0$, the effect disappears.

To broaden the consideration of the participation of entropic factors included in Eq. (18), an indicator assuming the hypothetic isoentropic condition, $\Delta S\left(P_{0}\right) \equiv 0$, is proposed in the form of:

$\mu=\frac{R T \ln \left(\frac{P_{0}}{P}\right)}{-\Delta H}$ or $\mu=\frac{R T \ln \left(\frac{P_{0}}{P}\right)}{q_{s t}}$ 
Fig. 3 (continued)
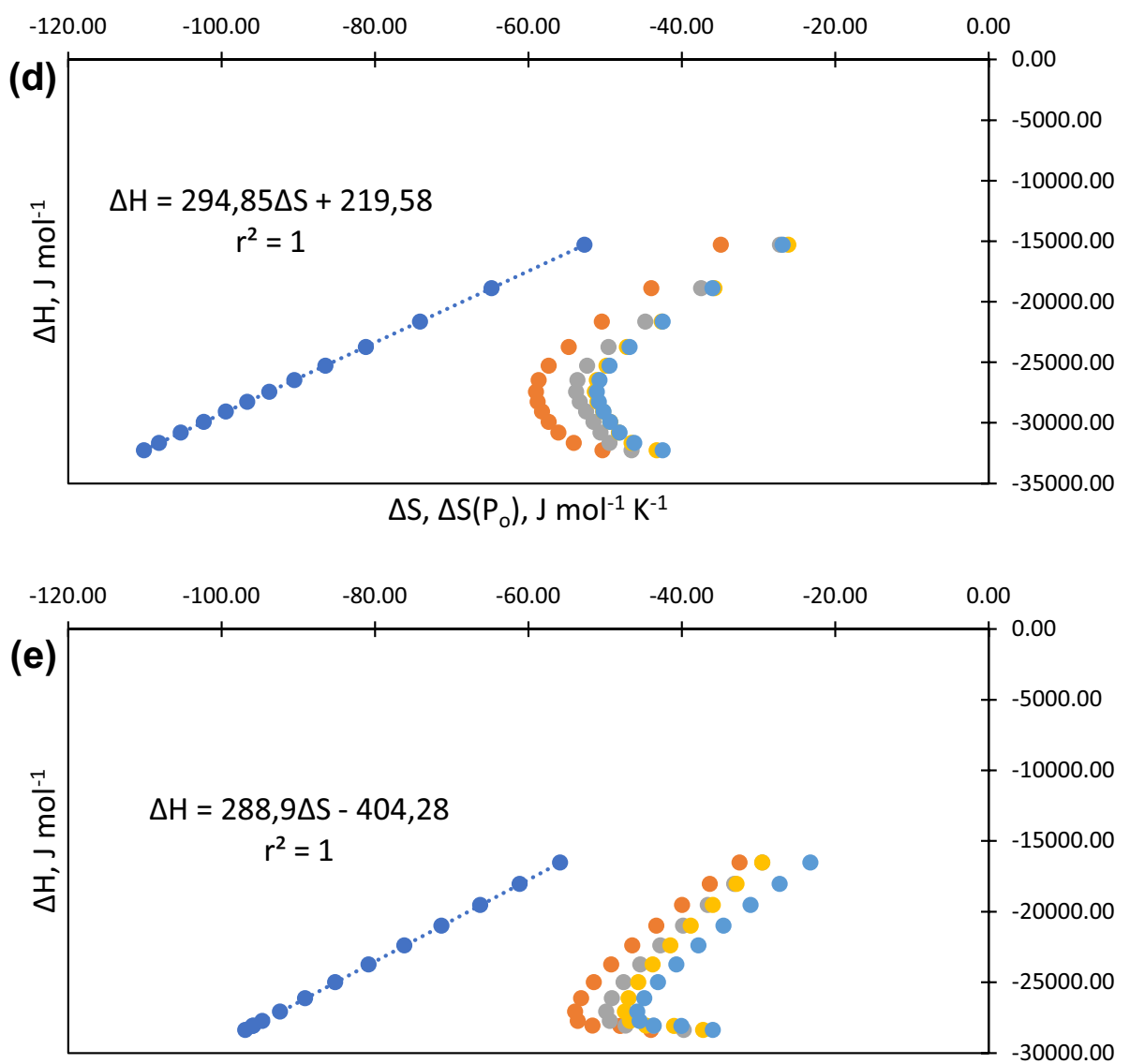

$\Delta \mathrm{S}, \Delta \mathrm{S}\left(\mathrm{P}_{\mathrm{o}}\right), \mathrm{J} \mathrm{mol}^{-1} \mathrm{~K}^{-1}$

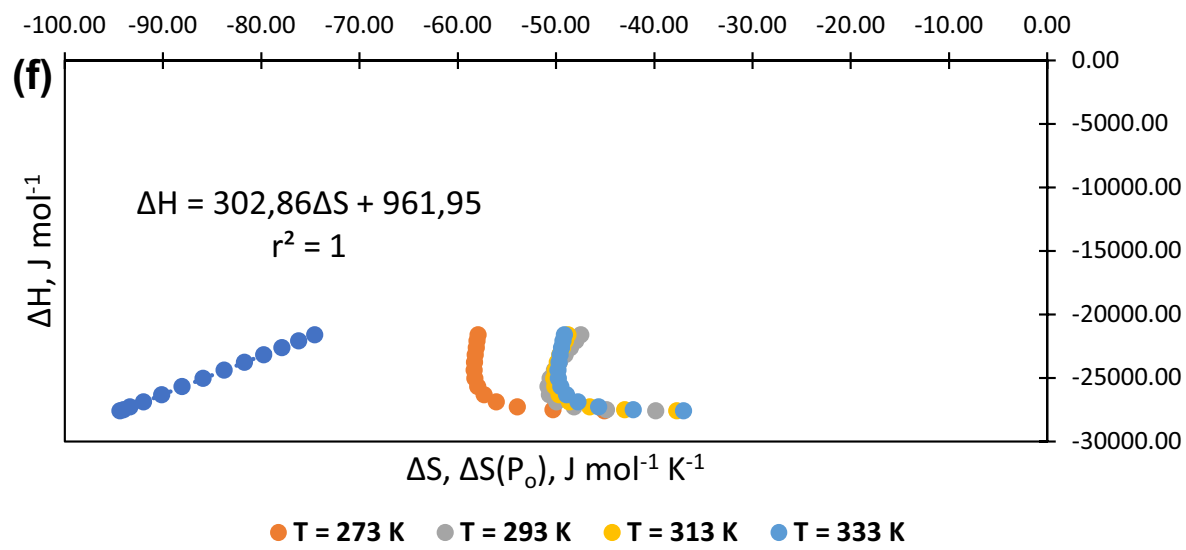

The scale of accepted values for presented data is within the range $0 \leq \mu \leq 1$, that is, for $\mu \rightarrow 0$, the experimental data becomes isosteric straight (see "x" on Figs. 3a, 4a), and for $\mu \rightarrow 1$, the experimental data shift away from the line (Figs. 3b, 4b). The other cases presented in Fig. 4 are complementary intermediate states.

For a deeper explanation, it was assumed $\mu=1$ and $\Delta S=0$, so $R \operatorname{Tln}\left(\frac{P_{0}}{P}\right) \equiv-\Delta H$. In this situation
$-R T \ln \left(\frac{P}{P_{o}}\right)>\Delta \mathrm{H}$ and next we have $R T \operatorname{Tn}\left(\frac{P}{P_{o}}\right)<\Delta \mathrm{H}$. Consistently, $\ln P-\ln P_{0}<\frac{\Delta H}{R T}$, what in the case of low value of $P$ can be written as $\ln P<\frac{\Delta H}{R T}+\ln P_{0}(T)$.

The interpretation can be changed by narrowing the temperature interval. Figure 5 shows an example. According to expectations for this variant, $\mu$ is in the range $\approx 0$ i.e., $<0.06 \div 0.15>,<0.06 \div 0.14>$, and $<0.08 \div 0.15>$, respectively, for $\mathrm{NaA}, \mathrm{NaX}$, and $\mathrm{NaY}$. 
Fig. 4 Dependence of the rate under the assumption of isoentropic conditions (25) as a function of adsorption for various data. [data $\mathrm{a}-\mathrm{d}$ from Fig. 2a-d and e, f from Fig. 3a, b in (Zukal et al. 2009)].
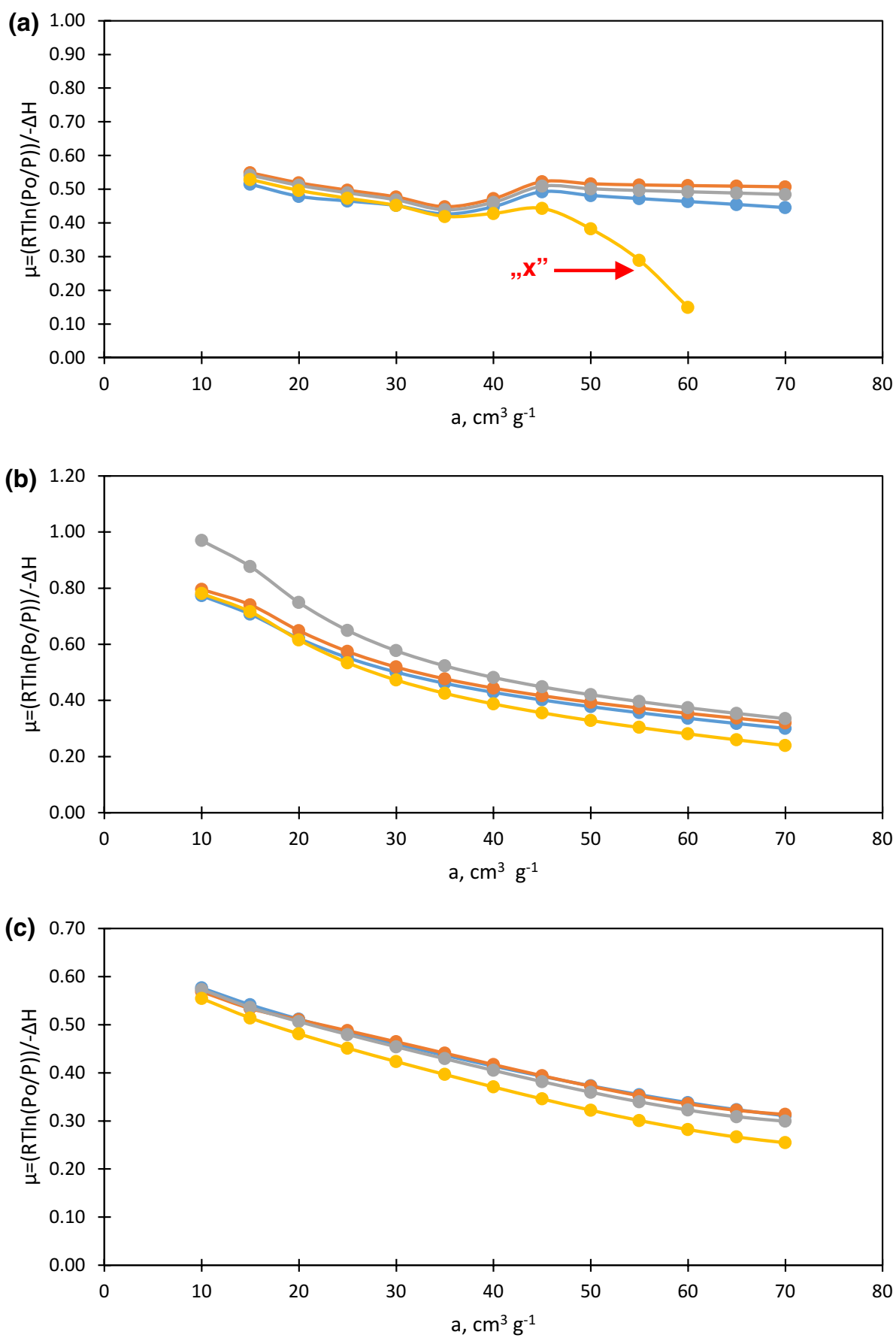

\subsection{Three-parametric equation}

The factor that inspires this type of research is the determination of the isosteric enthalpy of adsorption (with the opposite sign - heat of adsorption) based on the Clausius-Clapeyron equation [Eq. (3)]. Assuming a constant adsorption amount (a), after integration, the equation can be written in the form:

$\ln P=\frac{\Delta H}{R T}+\left.C\right|_{a}$
However, in many cases, the intercept depends on the amount of adsorption ( $a$ ), that is, $C=v a r$, because it depends on the entropy.

The right side of Eq. (26) can also be transcribed with respect to $T$, but, as in every polynomial method, this technique requires the estimation of many factors. Therefore, it is important to note that the enthalpy of adsorption $(\Delta H)$ blends into a different coefficient of member function $1 / T$. 
Fig. 4 (continued)
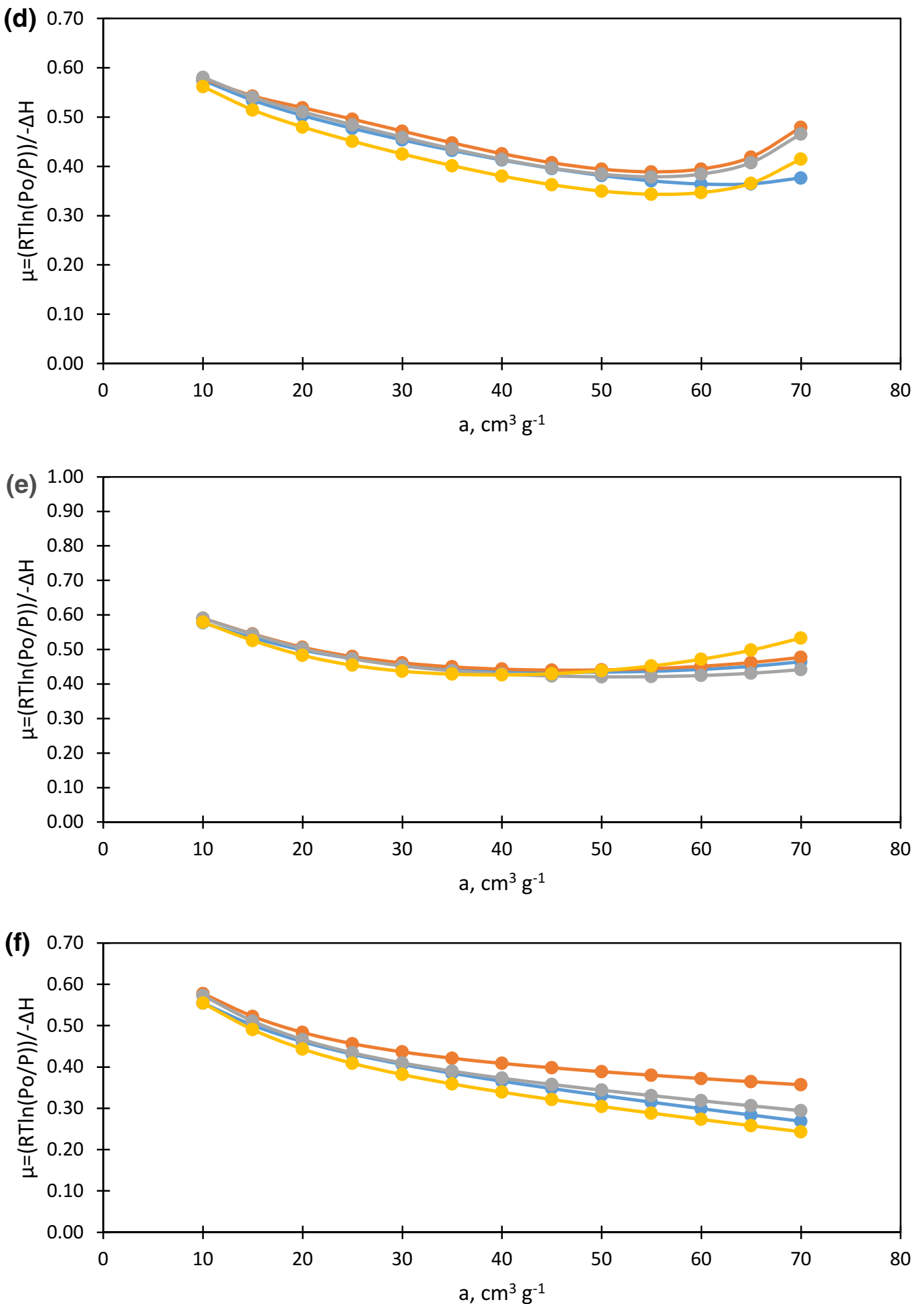

In 2000, the three-parameter equation published in (Mianowski 2000) was derived on the basis of the thermodynamics of reversible endothermic chemical reactions. A further work in this field [Eqs. (15-17) in (Mianowski and Urbańczyk 2016)] presented an equation for exothermic chemical reactions by turning the signs in relation to endothermic 
Fig. 5 The isosteric straight line created on the basis of Eqs. (3) and (18) [data from (Burevski et al. 1991)]



reactions $\left(a_{\mathrm{o}},-a_{1},-a_{2}\right)$. For adsorption processes, as proposed by the determination of the coefficients according to (Mianowski 2000):

$\ln P=-a_{3}+\frac{a_{4}}{T}+a_{5} \ln T, \quad a=i d e m$

Table 1 shows the three-parameter equation fitting on the experimental data.

The coefficients of the functional members in Eq. (27) satisfy the EEC in the form of a linear relationship:

$a_{4}=\frac{\Delta H}{R}+T_{\text {iso }} a_{5}$ which in practice enables tracking of the enthalpy variation in isosteric adsorption, wherein the intercept should be a negative number. Figure 6 shows this relationship (28).

The intercept can be used to determine the so-called point of zero enthalpy of adsorption (proposition an analytical version of the evaluation this thermodynamic value), i.e., for a hypothetical $\mathrm{a}=0$ and entropy:

$\Delta S(P)=\Delta H / T_{\text {iso }}$

Table 2 shows a comparison of the isosteric heat of adsorption calculated using the three-parameter equation for literature data (Zukal et al. 2009), and Table 3 shows the results of the calculation of the isosteric entropy of adsorption.
Table 1 The three-parameter equation fitting on the experimental data (Zukal et al. 2009)

\begin{tabular}{|c|c|c|c|c|c|c|c|c|c|c|c|c|}
\hline \multirow[t]{2}{*}{$\begin{array}{l}\mathrm{a}, \\
\mathrm{cm}^{3} \mathrm{~g}^{-1}\end{array}$} & \multicolumn{2}{|c|}{$\begin{array}{l}\mathrm{MCM}-22\left(\mathrm{~K}^{+}\right) \\
\mathrm{Si} / \mathrm{Al}=15\end{array}$} & \multicolumn{2}{|c|}{$\begin{array}{l}\mathrm{MCM}-22 \\
\left(\mathrm{Cs}^{+}\right) \\
\mathrm{Si} / \mathrm{Al}=15\end{array}$} & \multicolumn{2}{|c|}{$\begin{array}{l}\mathrm{MCM}-22 \\
\left(\mathrm{Li}^{+}\right) \\
\mathrm{Si} / \mathrm{Al}=15\end{array}$} & \multicolumn{2}{|c|}{$\begin{array}{l}\mathrm{MCM}-22 \\
\left(\mathrm{Na}^{+}\right) \\
\mathrm{Si} / \mathrm{Al}=15\end{array}$} & \multicolumn{2}{|c|}{$\begin{array}{l}\mathrm{MCM}-22 \\
\left(\mathrm{Na}^{+}\right) \\
\mathrm{Si} / \mathrm{Al}=20\end{array}$} & \multicolumn{2}{|c|}{$\begin{array}{l}\mathrm{MCM}-22 \\
\left(\mathrm{Na}^{+}\right) \\
\mathrm{Si} / \mathrm{Al}=40\end{array}$} \\
\hline & $\overline{r^{2}}$ & s.l. & $\overline{r^{2}}$ & s.l. & $\overline{r^{2}}$ & s.l. & $\overline{r^{2}}$ & s.l. & $\overline{r^{2}}$ & s.l. & $\overline{\mathrm{r}^{2}}$ & s.l. \\
\hline 15 & 0.9983 & 0.001 & 0.8754 & 0.005 & 0.9856 & 0.002 & 0.9889 & 0.002 & 0.9952 & 0.001 & 0.9930 & 0.001 \\
\hline 20 & 0.9985 & 0.001 & 0.9735 & 0.002 & 0.9859 & 0.002 & 0.9893 & 0.002 & 0.9970 & 0.001 & 0.9930 & 0.001 \\
\hline $2 J$ & 0.9979 & 0.001 & 0.9744 & 0.002 & 0.9888 & 0.002 & 0.9913 & 0.002 & 0.9981 & 0.001 & 0.9944 & 0.001 \\
\hline 30 & 0.9975 & 0.001 & 0.9745 & 0.002 & 0.9904 & 0.002 & 0.9923 & 0.001 & 0.9989 & 0.001 & 0.9965 & 0.001 \\
\hline J & 0.9965 & 0.001 & 0.9745 & 0.002 & 0.9909 & 0.002 & 0.9924 & 0.001 & 0.9995 & 0.001 & 0.9985 & 0.001 \\
\hline 40 & 0.9931 & 0.001 & 0.9884 & 0.002 & 0.9908 & 0.002 & 0.9922 & 0.001 & 0.9998 & 0.001 & 0.9998 & 0.001 \\
\hline 45 & 0.9833 & 0.002 & 914 & 0.002 & 0.9902 & 0.002 & 0.9918 & 0.001 & 1,0000 & 0.001 & 1.0000 & 0.001 \\
\hline 0 & 0.9824 & 0.002 & 0.9925 & 0.001 & 0.9896 & 0.002 & 0.9915 & 0.002 & 0.9999 & 0.001 & 1.0000 & 0.001 \\
\hline 55 & 0.9806 & 0.002 & 0.9929 & 0.001 & 0.9888 & 0.002 & 0.9915 & 0.002 & 0.9997 & 0.001 & 1.0000 & 0.001 \\
\hline 60 & 0.9950 & 0.001 & 0.9947 & 0.001 & 0.9882 & 0.002 & 0.9919 & 0.001 & 0.9992 & 0.001 & 1.0000 & 0.001 \\
\hline 65 & 0.9930 & 0.001 & 0.9948 & 0.001 & 0.9876 & 0.002 & 0.9928 & 0.001 & 0.9985 & 0.001 & 1.0000 & 0.001 \\
\hline 70 & 0.9976 & 0.001 & 0.9949 & 0.001 & 0.9872 & 0.002 & 0.9946 & 0.001 & 0.9976 & 0.001 & 1.0000 & 0.001 \\
\hline
\end{tabular}

$r^{2}$ correlation coefficient, s.l significance level 
Fig. 6 The dependence of the three-parameter equation's coefficients $\left(a_{4}\right.$ vs. $\left.a_{5}\right)$. [data $\mathrm{a}-\mathrm{d}$ from Fig. $2 \mathrm{a}-\mathrm{d}$ and $\mathrm{e}, \mathrm{f}$ from Fig. 3a, b in (Zukal et al. 2009)].


Returning to the signs in Eq. (27) we can observe inversion according to (Mianowski 2000; Mianowski and Urbańczyk 2016) for endothermic chemical reactions. In the case of adsorption this situation might be for small amount adsorbed substance (a) on carbonaceous adsorbents (activated carbon, coal) what related with swelling and dilation during carbon dioxide sequestration (Kelemen and Kwiatek 2009; Day et al. 2008; Czerw et al. 2016; Zarębska and Ceglarska-Stefańska 2008).
The values of the isosteric enthalpy of adsorption calculated for this case are consistent with the source data (Zukal et al. 2009).

\section{Discussion}

The relation between EEC (enthalpy-entropy compensation) and KCE (kinetics compensation effect) can be analyzed 
Fig. 6 (continued)


in different ways for chemical reactions/processes. In the case of adsorption processes, starting from the Langmuir isotherm to demonstrate the EEC (Clark 1970, p. 263) and analyzing the kinetics of adsorption, the equation of KCE can be obtained (Mianowski and Marecka 2009a, b).

The KCE relationship can be interpreted in terms of thermodynamics, in the simplest terms, for example, the thermodynamic functions of Eyring activation.

Assuming the isosteric entropy of adsorption for temperature-invariant conditions, analogous to the enthalpy in equilibrium conditions (7) and the record (9), it has been demonstrated that the EEC is related to three thermodynamic values: $\Delta H, \Delta S$ and $T$, which in a narrow temperature range determines the identity (24) without the intercept $\Delta H=T_{i s o} \Delta S$ or (29). By knowing the temperature range, the isosteric straight $H-S$ can be determined a priori, without research, because we know the value of the slope coefficient $\mathrm{T}_{\mathrm{iso}}$, which is the logarithmic or arithmetic average of the extreme temperature values. In this way, the EEC becomes a tautology and represents the modification of this effect, taking into account the possibility of a correlation between $\Delta H$ and $T \Delta S$, based on the 
Table 2 A comparison of source and calculated isosteric heat of adsorption, $\Delta H$ in $\mathrm{kJ} \mathrm{mol}^{-1}$ [data from (Zukal et al. 2009)]

\begin{tabular}{|c|c|}
\hline $\begin{array}{l}\mathrm{MCM}-22\left(\mathrm{~K}^{+}\right) \\
\mathrm{Si} / \mathrm{Al}=15\end{array}$ & $\begin{array}{l}-23.01 * \\
-22.69 * *\end{array}$ \\
\hline $\begin{array}{l}\mathrm{MCM}-22\left(\mathrm{Cs}^{+}\right) \\
\mathrm{Si} / \mathrm{Al}=15\end{array}$ & $\begin{array}{l}-47.41 * \\
-50.47 * *\end{array}$ \\
\hline $\begin{array}{l}\mathrm{MCM}-22\left(\mathrm{Li}^{+}\right) \\
\mathrm{Si} / \mathrm{Al}=15\end{array}$ & $\begin{array}{l}-44.21 * \\
-43.74 * *\end{array}$ \\
\hline $\begin{array}{l}\mathrm{MCM}-22\left(\mathrm{Na}^{+}\right) \\
\mathrm{Si} / \mathrm{Al}=15\end{array}$ & $\begin{array}{l}-43.59 * \\
-43.02 * *\end{array}$ \\
\hline $\begin{array}{l}\mathrm{MCM}-22\left(\mathrm{Na}^{+}\right) \\
\mathrm{Si} / \mathrm{Al}=20\end{array}$ & $\begin{array}{l}-25.07 * \\
-24.40 * *\end{array}$ \\
\hline $\begin{array}{l}\mathrm{MCM}-22\left(\mathrm{Na}^{+}\right) \\
\mathrm{Si} / \mathrm{Al}=40\end{array}$ & $\begin{array}{l}-33.98 * \\
-34.77 * *\end{array}$ \\
\hline \multicolumn{2}{|c|}{$\begin{array}{l}\text { *Source data (Zukal et al. 2009) } \\
\text { Authors of reference was cal- } \\
\text { culated the isosteric heat of } \\
\text { adsorption, } \Delta H, \mathrm{~J} \mathrm{~mol}^{-1} \text {, from } \\
\text { the slope of adsorption isosteres } \\
\text { using analogous Eq. (3) apply- } \\
\text { ing common logarithm instead } \\
\text { natural logarithm } \\
* * \text { Calculated }\end{array}$} \\
\hline
\end{tabular}

Table 3 Calculated isosteric entropy of adsorption, $\Delta S$ in $\mathrm{J} \mathrm{mol}^{-1}$ $\mathrm{K}^{-1}$ from (29)

\begin{tabular}{lr}
\hline MCM-22 $\left(\mathrm{K}^{+}\right) \mathrm{Si} / \mathrm{Al}=15$ & -78.27 \\
$\mathrm{MCM}-22\left(\mathrm{Cs}^{+}\right) \mathrm{Si} / \mathrm{Al}=15$ & -159.45 \\
$\mathrm{MCM}-22\left(\mathrm{Li}^{+}\right) \mathrm{Si} / \mathrm{Al}=15$ & -140.32 \\
$\mathrm{MCM}-22\left(\mathrm{Na}^{+}\right) \mathrm{Si} / \mathrm{Al}=15$ & -136.91 \\
$\mathrm{MCM}-22\left(\mathrm{Na}^{+}\right) \mathrm{Si} / \mathrm{Al}=20$ & -86.18 \\
$\mathrm{MCM}-22\left(\mathrm{Na}^{+}\right) \mathrm{Si} / \mathrm{Al}=40$ & -115.00 \\
\hline
\end{tabular}

integral form of the thermodynamic functions relative to the surface, as presented in (Pera-Titus 2016).

Because the entropy expression depends on the temperature, Eqs. (11), (17) and (18) deserve special attention in the commonly used approach (18). Using the balancing entropic factors (25), it is demonstrated that the scale of accepted values is within the range $0 \leq \mu \leq 1$, that is, for $\mu \rightarrow 0$, the experimental data approach the isosteric straight line (see " $x$ " on Figs. 3a, 4a) and for $\mu \rightarrow 1$, due to the inclusion of entropy, the experimental data shift away from that line (Figs. 3b, 4b). Other cases presented in Fig. 4 are complementary intermediate states. The EEC follows a linear relationship in relation to the saturated vapor pressure $\mathrm{P}_{0}$ in fairly narrow ranges of variation. For the initial conditions, with equilibrium vapor pressure close to 0 , there are significant distances from the isosteric straight $H-S$ or even opposite linear direction changes. These conclusions are related to the variability in a single system: adsorbent - adsorbate in a narrow temperature range. If we observe linear relationships in accordance with the direction of the isosteric straight line, the intercept is important, so the right correct relationship is (1).

The adsorption process considerations show that the determination of isosteric enthalpy of adsorption is most important, whereas for analysis of the EEC for a system with a variable amount of adsorbed substance $(a)$, there are several possibilities to calculate the entropy.

Note, however, that:

1. the same phenomena are observed,

2. in accordance with the definition of entropy in Eq. (8) and Eqs. (15) and (16), a change in the entropy of gas $\left[s_{G}\right.$ acc. Eq. (8)] is observed because of the immediate surroundings to $H-S$. Therefore, we observe a sequence of observations due to the changing point of reference: $H-S, \Delta S(P), \Delta S\left(P^{\emptyset}\right), \Delta S\left(P_{o}\right)$.

In the following, it is suggested that the analysis can be performed using a three-parameter equation Eq. (27) according to (Mianowski 2000) with the signs changed, which is characteristic of an exothermic process. The mathematical structure of the three-parameter Eq. (27) corresponds to the Kirchhoff-Rankine-Dupre correlation (Bogillo and Staszczuk 1999). In turn, Eq. (28) can be seen as another form of the EEC, wherein the thermodynamic values are for a hypothetical point of zero adsorption $(a)$. Therefore, this is a new analytical version of the evaluation of the heat of adsorption and is appropriate for the entropy under isosteric conditions, as in Eq. (29), and also as a temperature-dependent value (11).

\section{Calculation techniques and methodology}

Similar to approach (3) and its simplest version (26), the last equation can be expanded to the form of the polynomial. The left side of the algorithm represents (26) $\ln P=$ polynomial virial-type comprising members depending on the amount of gas adsorbed and the temperature (Czepirski and Jagiełło 1989). Therefore, this is a more universal approach. However, Eq. (27) makes physical sense, and the number of parameters to determine is limited to three. This paper uses the six isotherms ( $a$ vs. $P$ ) shown in (Zukal et al. 2009) that have been scanned and converted to an inverse function $P$ or $\ln P=$ third-degree polynomial in relation to $a$. The selection was determined based on the result of an $F$-test, which indicated that it was advantageous to accept of one form, in view of the selected number of degrees of freedom. The equation was accepted when the $F$-test showed a much higher value.

The data in (Burevski et al. 1991) were scanned data from the Dubinin-Astakhov chart [Fig. 1 in (Burevski et al. 1991)] with simultaneous unravel proposed by the authors as functions of the calculated values: $R \ln \left(P_{o} / P\right)$ using data 
Table 4 Details of the used experimental data from (Burevski et al. 1991; Zukal et al. 2009)

\begin{tabular}{|c|c|c|}
\hline Details of the experimental data & Burevski et al. (1991) & Zukal et al. (2009) \\
\hline Experimental method & $\begin{array}{l}\text { The adsorption measurements were carried out by the } \\
\text { flow method }\end{array}$ & $\begin{array}{l}\text { The adsorption measurements were carried out by } \\
\text { static volumetric apparatus ASAP (2020) }\end{array}$ \\
\hline Adsorbate(s) & Carbon dioxide $\left(\mathrm{CO}_{2}\right)$ & \\
\hline Adsorbent(s) & $\begin{array}{l}\text { Commercially available zeolite } \mathrm{NaA}, \mathrm{NaX}, \mathrm{NaY} \text { (Che- } \\
\text { miekombinat Bitterfeld) }\end{array}$ & $\begin{array}{l}\text { The authors of reference synthesized Na-MCM-22 } \\
\text { zeolites with } \mathrm{Si} / \mathrm{Al} \text { ratios in the range from } 15 \text { to } 40 \\
\text { with sodium aluminate (50-56\% } \mathrm{Al}_{2} \mathrm{O}_{3}, 40-45 \% \\
\mathrm{Na}_{2} \mathrm{O} \text {, Riedel-de Haën). As a source of aluminum } \\
\text { and silicon they used Cab-OSil } \mathrm{M} 5 \text { (Cabot } \mathrm{GmbH}) \text {. } \\
\text { This zeolite (Na-MCM-22) authors was used as } \\
\text { starting material for cation exchange ( } 1.0 \mathrm{M} \mathrm{MNO} \\
\text { water solutions }\left(\mathrm{M}=\mathrm{Na}^{+}, \mathrm{K}^{+}, \mathrm{Cs}^{+}\right) \text {or } \mathrm{LiCl} \text { in the } \\
\left.\text { case of } \mathrm{Li}^{+}\right)\end{array}$ \\
\hline Temperature (K) & 288 and 298 & $273,293,313$ and 333 \\
\hline Pressure & $\begin{array}{l}\text { The partial pressure of } \mathrm{CO}_{2} \text { was calculated from the } \\
\text { flow values of the gases }\end{array}$ & $\begin{array}{l}\text { Pressure of adsorption in the range } 1-800 \text { Torr } \\
\quad(0.133-106.7 \mathrm{kPa})\end{array}$ \\
\hline
\end{tabular}

presented in this work [Eq. (6) and Table 1 in (Burevski et al. 1991)].

The values of $\mathrm{P}_{\mathrm{o}}$ for $\mathrm{CO}_{2}$ for temperatures $t=0-30{ }^{\circ} \mathrm{C}$ were taken from tables in (TEGA 2016), and the values for higher temperatures were taken from the Dubinin formula in (Seewald and Klein 1986; Amankwah and Schwarz 1995; Cavenati et al. 2004) and the critical parameters [acc. Table 4, p. 1519-1520 in (Span and Wagner 1996)]:

$P_{o}=7,377(T / 304,13)^{2}, \mathrm{MPa}$
Fig. 7 a EEC system for literature data of benzene adsorption on zeolite MFI-6 Eqs. (3) and (18) and isosteric straight (light blue) based on Eqs. (3) and (9) (temperature range 273-293 K) b the dependence of the threeparameter equation's coefficients $\left(a_{4}\right.$ vs. $\left.a_{5}\right)$ [data from Fig. 4 in (Pera and Llorens 2010)]. (Color figure online)
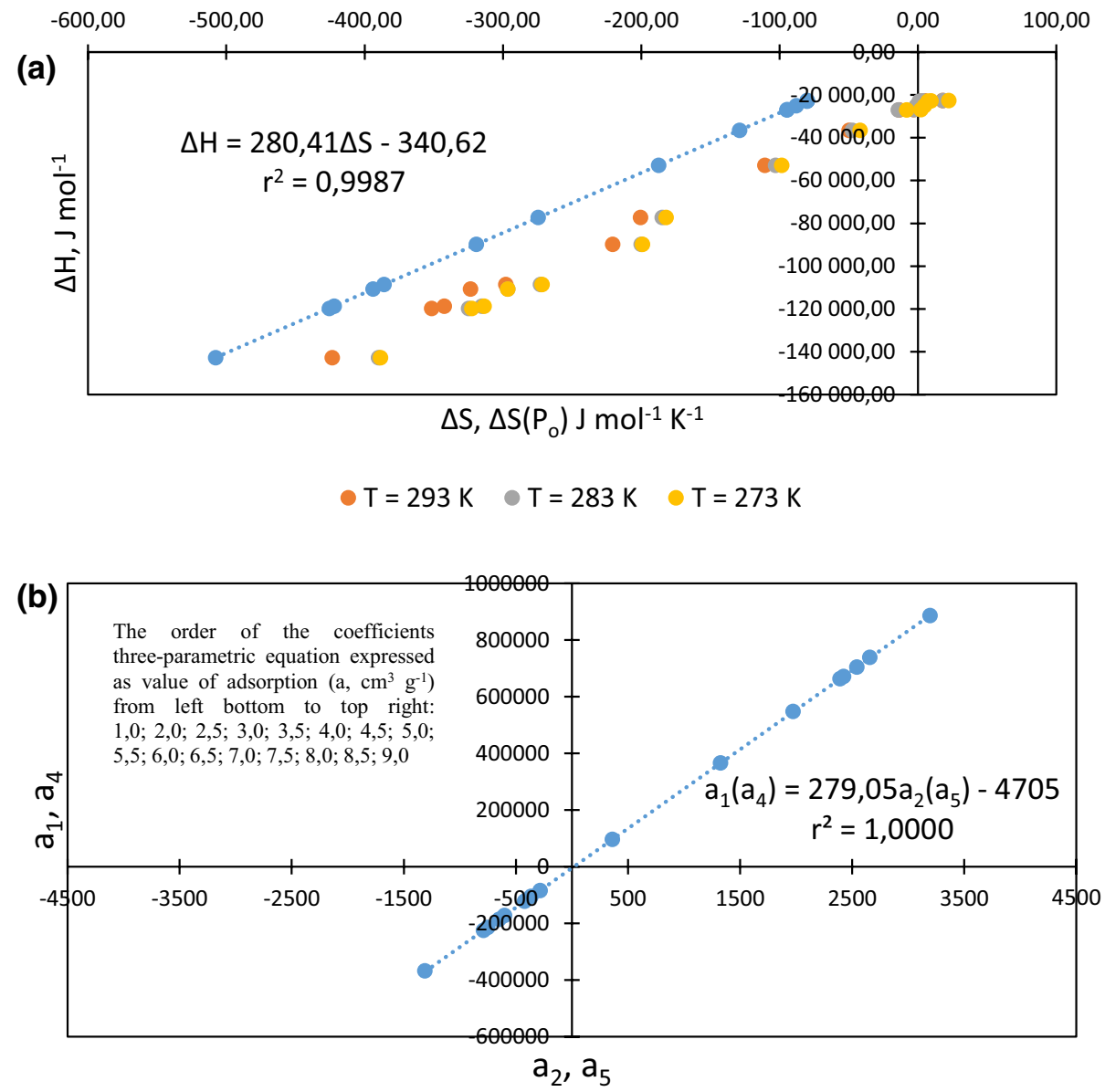
Table 4 shows the methodology of research for Figs. 1, 3 and 5 originate from references (Burevski et al. 1991; Zukal et al. 2009).

The presented physicochemical background is not applicable only for $\mathrm{CO}_{2}$ adsorption on zeolites. Analogous results were obtained for different combinations e.g. benzene adsorption on MFI-6 zeolite at near ambient temperatures (273-293 K) (authors of reference (Pera and Llorens 2010) was obtained the adsorption isotherms from $G C$-MC simulation) or n-hexane adsorption on 5 A zeolite (Garcia-Perez et al. 2006). Figure 7 shows an example.

\section{Conclusions}

1. The isosteric straight, represented by $H-S$, characterizes the EEC in a simple form: $\Delta H=T_{i s o} \Delta S$. For isosteric conditions, various thermodynamic functions are calculated in Eqs. (3) and (9). By knowing the range of temperature variation, the isosteric straight $H-S$ can be determined a priori, without research, because we know the value of the slope coefficient $T_{i s o}$. It is the logarithmic or arithmetic average of the extreme temperature values.

2. Because the expression of entropy depends on the temperature, Eqs. (11), (17) and (18) deserve special attention in the commonly used approach (18). Using the measure of the balancing entropic factors (25), it is demonstrated that the scale of accepted values is within the range $0 \leq \mu \leq 1$, that is, for $\mu \rightarrow 0$, the experimental data become isosteric straight (see " $x$ " on Figs. 3a, 4a) and for $\mu \rightarrow 1$, due to the participation of entropy, the experimental data move away from the isosteric straight $H-S$.

3. Due to the important role of entropy in explaining the EEC, in line with Starikov (2014), it is necessary to specify what values are the determinant conditions. Its values are $10^{3}$ times smaller than those of enthalpy or different-isosteric heat of adsorption. Depending on the determination of the entropy, $\Delta H_{\text {iso }}$ may be 0 or take a small value, wherein these data refer to the system: zeolite- $\mathrm{CO}_{2}$.

4. Compared to conventional considerations, the threeparameter Eq. (27) and the EEC in (28), significantly enhance the possibility of analyzing the experimental data for the adsorption process. Therefore, this is new analytical version of the evaluation of the heat of adsorption is appropriate for entropy under isosteric conditions using Eq. (29) and also for temperaturedependent values (11).
Acknowledgements We would like to express our sincere gratitude to Dr Eng. Aleksandrze MARECKIEJ Faculty of Energy and Fuels, AGH, Kraków for the interest in the subject and the valuable discussions.

Open Access This article is distributed under the terms of the Creative Commons Attribution 4.0 International License (http://creativecommons.org/licenses/by/4.0/), which permits unrestricted use, distribution, and reproduction in any medium, provided you give appropriate credit to the original author(s) and the source, provide a link to the Creative Commons license, and indicate if changes were made.

\section{References}

Al-Muhtaseb, A.H., McMinn, W.A.M., Magge, T.R.A.: Water sorption isotherm of starch powders. Part 2: thermodynamic characteristics. J. Food Eng. 62, 135-142 (2004)

Al-Muhtaseb, S.A., Abu Al-Rub, F.A., Al Zarooni, M.: Adsorption equilibria of nitrogen, methane and ethane on $\mathrm{BDH}$-activated carbon. J. Chem. Eng. Data. 52, 60-65 (2007)

Amankwah, K.J.A.G., Schwarz, J.A.: A modified approach for estimating pseudo-vapor pressures in the application of the DubininAstakhov equation. Carbon. 33, 1313-1319 (1995)

Aphornratana, S., Eames, I.W.: Thermodynamic analysis of absorption refrigeration cycles using the second law of thermodynamic method. Int. J. Refrig. 18, 244-252 (1995)

Barin, I.: Thermochemical Data of Pure Substance. VCH, Weinheim (1997)

Barrer, R.M., Gibbons, R.M.: Zeolitic ammonia. Part 2. Free energy and entropy. Trans. Faraday Soc. 59, 2875-2887 (1963a)

Barrer, R.M., Gibbons, R.M.: Zeolitic ammonia. Part 1. Sorbed fluid and heat of sorption. Trans. Faraday Soc. 59, 2875-2887 (1963b)

Beristain, C.I., Garcia, H.S., Azuara, E.: Enthalpy-entropy compensation in food vapor adsorption. J. Food Eng. 30, 405-425 (1996)

Bogillo, V.I., Staszczuk, P.: Characterization of the structural and energetic heterogeneity of mesoporous solid surfaces from Q-DTG data. J. Therm. Anal. Calorim. 55, 493-510 (1999)

Borsukiewicz-Gozdur, A., Nowak, W.: Comparative analysis of natural and synthetic refrigerants in application to low temperature Clausius-Rankine cycle. Energy. 32, 344-352 (2007)

Burevski, D., Pilchowski, K., Bergk, K.H.: Evaluation of thermodynamic data of adsorption of carbon dioxide on $\mathrm{NaA}, \mathrm{NaX}$ and NaY zeolites. Croat. Chem. Acta. 64, 199-205 (1991)

Cavenati, S., Grande, C.A., Rodrigues, A.E.: Adsorption equilibrium of methane, carbon dioxide, and nitrogen on zeolite $13 \mathrm{X}$ at high pressures. J. Chem. Eng. Data. 49, 1095-1101 (2004)

Clark, A.: The theory of adsorption and catalysis. Academic Press, New York (1970)

Czepirski, L., Jagiełło, J.: Virial-type thermal equation of gas-solid adsorption. Chem. Eng. Sci. 44, 797-801 (1989)

Czerw, K., Zarębska, K., Buczek, B., Baran, P.: Kinetic models assessment for swelling of coal induced by methane and carbon dioxide sorption. Adsorption 22, 791-799 (2016)

Day, S., Fry, R., Sakurovs, R.: Swelling of Australian coals in supercritical $\mathrm{CO}_{2}$. Int. J. Coal Geol. 74, 41-52 (2008)

de Marco, D., Linert, W.: Thermodynamic relationships in complex formation. IX. $\Delta \mathrm{H}-\Delta \mathrm{S}$ and free energy relationships in mixed ligand complex formation reactions of $\mathrm{Cd}(\mathrm{II})$ in aqueous solution. J. Chem. Thermodyn. 34(8), 1137-1149 (2002)

Dutronc, T., Terazzi, E., Piguet, C.: Melting temperatures deduced from molar volumes: a consequence of the combination of enthalpy/ entropy compensation with linear cohesive free-energy densities. RSC Adv. 4, 15740-15748 (2014) 
Fletcher, A.J., Thomas, K.M.: Compensation effect for the kinetics of adsorption/desorption of gases/vapors on microporous carbon materials. Langmuir. 16, 6253-6266 (2000)

Garcia-Perez, E., Dubbeldam, D., Maesen TLM, Calero, S.: Influence of cation $\mathrm{Na} / \mathrm{Ca}$ ratio on adsorption in LTA 5A: a systematic molecular simulation study of alkane chain length. J. Phys. Chem. B. 110, 23968-23976 (2006)

Garrone, E., Bonelli, B., Otero Areán, C.: Enthaply-entropy correlation for hydrogen adsorption on zeolites. Chem. Phys. Lett. 456, 68-70 (2008)

Gauden, P.A., Furmaniak, S., Włoch, J., Terzyk, A.P., Zieliński, W., Kowalczyk, P., Kurzawa, J.: The influence of geometric heterogeneity of closed carbon nanotube bundles on benzene adsorption from the gaseous phase - Monte Carlo simulations. Adsorption 22, 639-651 (2016) (and supporting information)

Guo, B., Chang, L., Xie, K.: Adsorption of carbon dioxide on activated carbon. J. Nat. Gas Chem. 15, 223-229 (2006)

Gwadera, M., Kupie, K.: Adsorpcyjne układy chłodnicze. Inż. Ap. Chem. 50, 38-39 (2011) (in Polish)

Hassan, H., Mohamad, A.A., Bennacer, R.: Simulation of an adsorption solar cooling system. Energy. 36, 530-537 (2011)

Hercigonja, R., Rakić, V.: Enthalpy-entropy compensation for n-hexane adsorption on zeolite $\mathrm{X}$, containing transition metal cations. In: Abstracts of the Proceedings 5th Serbian-Croatian-Slovenian Symposium on Zeolites, Zlatibor, Serbia, 30 May - 2 June 2013

Kelemen, S.R., Kwiatek, L.M.: Physical properties of selected block Argonne Premium bituminous coal related to $\mathrm{CO}_{2}, \mathrm{CH}_{4}$ and $\mathrm{N}_{2}$ adsorption. Int. J. Coal Geol. 77, 2-9 (2009)

Kelut, P., Kulkarni, K., Kulkarni, A.D. (2014) $\mathrm{CO}_{2}$ adsorption by various catalysts. Chem. Proc. Eng. Res. 18, 7-15

Klebe, G.: Applying thermodynamic profiling in lead finding and optimization. Nat. Rev. Drug Discov. 14, 95-110 (2015). doi:10.1038/ $\operatorname{nrd} 44865$

Korolev, A.A., Shiryaeva, V.E., Popova, T.P., Kurganov, A.A.: Enthalpyentropy compensation effect on adsorption of light hydrocarbons on monolithic stationary phases. J. Sep. Sci. 34, 2362-2369 (2011)

Kowalczyk, P., Gauden, P.A., Furmaniak, S., Terzyk, A.P., Wiśniewski, M., Ilnicka, A., Łukaszewicz, J., Burian, A., Włoch, J., Neimark, A.V.: Morphologically disordered pore model for characterization of micro-mesoporous carbons. Carbon. 111, 358-370 (2017)

Loto, R.T., Loto, C.A., Popoola, A.P.I.: Effect of aminobenzene concentrations on the corrosion inhibition of mild steel in sulphuric acid. Int. J. Electrochem. Sci. 7, 7016-7032 (2012)

Lvov, B.V.: Thermal decomposition of solids and melt. Springer, Berlin (2007)

Madamba, P.S., Driscoll, R.H., Buckle, K.A.: Enthalpy-entropy compensatiom models for sorption and browning of garlic. J. Food Eng. 28, 109-119 (1996)

Mianowski, A.: Thermal dissociation in dynamic conditions by modeling thermogravimetric curves using the logarithm conversion degree. J. Therm. Anal Calorim. 59, 747-762 (2000)

Mianowski, A., Marecka, A.: Arrhenius law in the investigations of energetic on the example of sorption kinetics of gases on coal at ambient temperatures. Part I. Fick's diffusion and parameter estimated from kinetic curves. J. Therm. Anal Calorim. 95(1), 285-292 (2009a)

Mianowski, A., Marecka, A.: Arrhenius law in the investigations of energetic on the example of sorption kinetics of gases on coal at ambient temperatures. Part II Fick's dissusion and isokinetic effect. J. Therm. Anal. Calorim. 96(2), 495-499 (2009b)

Mianowski, A., Urbańczyk, W.: Thermal dissociation in terms of the second law of chemical thermodynamics. J. Therm. Anal. Calorim. 126, 863-870 (2016)

Musa, A.Y., Kadhum, A.A.H., Mohamad, A.B., Takriff, M.S., Daud, A.R., Kamarudin, S.K. (2010) On the inhibition of mild steel corrosion by 4-amino-5-phenyl-4H-1,24-trizole-3-thiol. Corros. Sci. 52, 526-533
Norwisz, J., Musielak, T. (2007) Compensation law again. J. Therm. Anal. Calorim. 88, 751-755

Olsson, T.S.G, Williams, M.A., Pitt, W.R., Lanbury, J.E.: The thermodynamics of protein-ligand interaction and solvation: insights for ligand design. J. Mol. Biol. 384, 1002-1017 (2008). doi:10.1016/j. jmb.2008.09.073

Ościk, J.: Adsorpcja. 3rd edn. PWN, Warszawa (1983) (in Polish)

Palomino, G.T., Carayol MRL, Otero Areán, C.: Thermodynamics of hydrogen adsorption on zeolite Ca-Y. Catal. Today. 138, 249-252 (2008)

Pedro, M.A.M., Babas, A.L.: Enthalpy-entropy compensation based on isotherm of mango. Ciênc. Tecnol. Aliment. Campinas 25, 297-303 (2005)

Pera-Titus, M.: Direct inference of site strength in basic solids upon $\mathrm{CO}_{2}$ adsorption: enthalpy-entropy compensation effect. Phys. Chem. Chem. Phys. 18, 22548-22556 (2016). doi:10.1039/C6CP03941C

Pera-Titus, M., Llorens, J.: Evaluation of confinement effects in zeolites under Henry's adsorption regime. Appl. Surf. Sci. 256, 5305-5310 (2010)

Ramesh, A., Lee, D.J., Wong, J.W.C.: Thermodynamic parameters for adsorption equilibrium of heavy metals and dyes from wastewater with low-cost adsorbents. J. Colloid Interface Sci. 291, 588-592 (2005)

Rouquerol, F., Rouquerol, J., Sing, K.: Adsorpton by powders and porous solids, principles, methodology and applications. Academic Press, London (1999)

Ryde, U.: A fundamental view of enthalpy-entropy compensation. Med. Chem. Commun. 5, 1324-1336 (2014)

Seewald, K., Klein, J.: Methane sorption an Steinkohle und Kennzeichnung der Porenstruktur. Glückauf-Forschungshefte 47(3), 149-156 (1986)

Sharp, K.: Entropy-enthalpy compensation: fact or artifact? Protein Sci. 10(3), 661-667 (2001)

Sircar, S., Mohr, R., Ristic, C., Rao, M.B.: Isosteric heat of adsorption: theory and experiment. J. Phys. Chem. B. 103, 6539-6546 (1999)

Span, R., Wagner, W.: A new equation of state for carbon dioxide covering the fluid region from the triple-point temperature to 1100 $\mathrm{K}$ at pressures up to $800 \mathrm{MPa}$. J. Phys. Chem. Ref. Data. 25(6), 1509-1596 (1996)

Stadie, N.P., Murialdo, M., Ahn, C.C., Fultz, B.: Anomalous isosteric enthalpy of adsorption on zeolite-templated carbon-supporting information. JACS 135, 990-993 (2012)

Starikov, E.B.: "Meyer-Nedel Rule": true history of its development and its intimate connection to classical thermodynamics. J. Appl. Sol. Chem. Model. 1, 15-31 (2014)

Sumathy, K., Yeung, K.H., Yong, L: Technology development in the solar adsorption refrigeration systems. Progr. Energy Combust. Sci. 29, 301-327 (2003)

Tang, L., Li, X., Li, L., Mu, G., Liu, G.: The effect of 1-(2-pyridylazo)2-naphthol on the corrosion of cold rolled steel in acid media, Part 2: inhibitive action in $0.5 \mathrm{M}$ sulfuric acid. Mater. Chem. Phys. 97, 303-307 (2006)

TEGA (2016) Saturation Table $\mathrm{CO}_{2}$. http://www.lindegas.ro/internet. lg.lg.rou/ro/images/R74454_138675.pdf. Accessed 20 Nov 2016

Terzyk, A.P., Furmaniak, S., Wiśniewski, M., Werengowska, K., Gauden, P.A., Kowalczyk, P.: New findings on the influence of carbon surface curvature on energetics of benzene adsorption from gaseous phase. Chem. Phys. Lett. 645, 157-163 (2016)

Zarębska, K., Ceglarska-Stefańska, G.: The change in effective stress associated with swelling during carbon dioxide sequestration on natural gas recovery. Int. J. Coal Geol. 74, 167-174 (2008)

Zukal, A., Pawlesa, J., Čejka, J.: Isosteric heats of adsorption of carbon dioxide on zeolite MCM-22 modified by alkali metal cations. Adsorption 15, 264-270 (2009) 